\title{
Teacher perceptions of managing indiscipline amongst at-risk teenage students: A Malaysian study
} \author{
Jamalullail Ab. Wahab ${ }^{1}$ \\ ${ }^{1}$ Faculty of Education, Universiti Kebangsaan Malaysia, Bangi, Malaysia \\ 2Faculty of Education, Open University Malaysia, Kuala Lumpur, Malaysia
}

Azlin Norhaini Mansor ${ }^{1,}$, Jayanthi Sanasi ${ }^{2}$, Mohamed Yusoff Mohd Nor ${ }^{1}$, Nurfaradilla Mohamad Nasir ${ }^{1}$,

\section{A R T I CLE IN F O}

Article history:

Received 10 January 2017

Received in revised form

10 April 2017

Accepted 19 April 2017

\section{Keywords:}

Indiscipline

At-risk

Qualitative

Truancy

Management

\begin{abstract}
A B S T R A C T
This study aims to identify factors contributing to disciplinary issues, and observe measures currently in operations that manage this behaviour. Data for this qualitative case study include interviews from 10 respondents who are subject teachers, discipline teachers, and school counsellors at one urban secondary schools in Malaysia. This study concludes the home environment, peer influence, social expectation, school culture, the Media, and informationcommunication technology are identified as salient factors contributing to indiscipline in schools. Constructive strategies to manage indiscipline include effective classroom management, humane-environmental awareness planning, strong school leadership, and pupil-peer mentoring systems. A comprehensive study involving larger samples of schools and respondents is suggested to develop further reliable strategies to address at-risk student indiscipline and dropout.
\end{abstract}

(C) 2017 The Authors. Published by IASE. This is an open access article under the CC BY-NC-ND license (http://creativecommons.org/licenses/by-nc-nd/4.0/).

\section{Introduction}

Whilst researchers view education as a means of knowledge development, schools are also social institutions that accommodate students with great cultural and ethnic diversity. Schools play a vital role in producing knowledgeable and skilled individuals, and are institutions where students learn accountability and responsibility alongside discipline needed to engage in behavioural norms (Chevalier and Buckles, 2013). NMSA (2003) viewed school as a central organizing experience in a teenager's life. School offers opportunities to learn information, master new skills and sharpen old ones to participate in various school activities that explore vocational choice, and learn to socialize. In this way, schools set out to widen a student's spectrum of intellectual and social horizons. Not all teenagers, however, experience school not as an opportunity but as a hindrance on the road to adulthood.

Negative attitudes and disruptive behaviours are not the aim of any school, and school systems still face adversities and challenges to produce students who are self-disciplined with positive values and

\footnotetext{
* Corresponding Author.

Email Address: azlinmansor@ukm.edu.my (A. N. Mansor) https://doi.org/10.21833/ijaas.2017.05.020

2313-626X/C 2017 The Authors. Published by IASE.

This is an open access article under the CC BY-NC-ND license

(http://creativecommons.org/licenses/by-nc-nd/4.0/)
}

norms. Discipline problems in schools have always been a major concern for teachers and educators, and increases in the intensity of this behaviour towards a confrontational nature are now common (Chazan et al., 2014).

Failure in dealing with indiscipline in schools results from ineffective school management and addressing discipline problems in schools requires a fundamental change of management mind-set. Most relevant research concludes punitive approaches to resolving discipline issues only support students in the short-term. Shelley and Natalie (2006) revealed that suspension and expulsion are ineffective in curbing discipline problems. Truancy for example, needs school administrators to find out the cause for absence; fighting requires restorative, socially acceptable resolutions. Shelley and Natalie (2006) observed that students may have a variety of reasons for skipping school, significantly peer victimization, anxiety, and maltreatment. Oppositional and conduct disordered youth may also be seeking support outside of the school context. Reactive responses, including suspension and expulsion typically address the symptoms and not the causes of behaviour. Shelley and Natalie (2006) added that students who display aggressive and oppositional behaviours at school are expressing their need for help.

Indiscipline can be seen as a symptom (Onyije and Ojedapo, 2010). Finding the factors that produce the symptoms of discipline problems is a challenge 
because each child's needs and background are different. In resolving indiscipline, schools and community need to help students find alternative ways to address the problems that they face that cannot be addressed without adult support; this implicates school teachers and counsellors. In addition, working effectively with students who have significant discipline and behavioural challenges, educators must understand the quality of relationship between students and teachers, other students, and ultimately, the child's relationship to the school. A growing body of research demonstrates the importance of student bonding to school, to classmates, and to teachers (Baker et al., 2008; O'Connor et al., 2011; Silver et al., 2005).

Research conclusions suggest early identification and intervention programmes that consider the individual behavioural and academic challenges of students. Reviews also mention that school climate plays important roles in overcoming discipline problems in schools. Schools are encouraged to foster social-emotional learning and create positive school climates in order to create a safe and caring learning environment in which negative behaviour is not encouraged. Studies also suggest that teachers who work with high risk youth require specialized training, and collaborate with outside agencies when appropriate, such including the police, religious bodies and community centers.

\section{Indiscipline causes}

Indiscipline occurs when students refuse to obey the rules and regulations of schools (Yahaya et al., 2012). Acts of indiscipline begin when students fail to learn self-discipline (positive learning behaviour) or confront school rules and regulations. Cotton and Wikelund (1990) added that discipline problems can disrupt the flow of classroom activities and interfere learning activities.

That newspapers and electronic media highlight the increase of discipline problems such as truancy, absenteeism, stealing and fighting among secondary school students illustrates the seriousness of the problem (MOE, 2013). Truancy is becoming the major discipline problem among secondary students. Based on Yahaya et al. (2009), 24,840 students in 2006, and 21,060 in 2007 truanted from school. Of the eight types of discipline problems listed by MOE, truancy was then ranked second highest after 'lack of politeness'. Other discipline problems, amongst disorderliness such as time-wasting and dress/uniform, include actions that are criminal in nature: Delinquency, vandalism and obscenity (Desa et al., 2012).

Many factors contribute to indiscipline in schools such as peer group influence, family or parental, social or environmental factor and, development of media and communication technology. Peer influence is the second most salient factor in causing disruptive behaviour among students according to Morales (1982). Peers that display irresponsibility disobeys rules are uncooperative, disengaged with academic work, and time mismanagement prevail the discipline problem. Morales suggest a peer group is the social connections to youth that provide moral support in seeking personal identity. Teenagers like to seek satisfaction and knowledge that is relevant to their lifestyle. Relationships and peer influences lead to newer culture in life. Papalia and Olds (1978), stated that good and healthy interactions between teen peers can develop positive behaviours such as tolerance, respect, and mutual support without which individual behaviour can markedly deteriorate.

Family plays an important role in the development of a teenager's personality and in leading children to correct paths in life. Shahizan et al. (2005) stated that good relationships between parents and children help them to think positively about themselves and others, unlike students who are parentally neglected. Good interaction between parents and children make children feel appreciated, loveable, and responsible and learn mutual trust and sound judgment for life. Moreover, the roots of delinquency mostly lie within the family relationships and family environment. Parents of chronic delinquents often fail to reinforce positive behaviour in early childhood, are harsh, or use punishment inconsistently (Crosnoe, 2006).

School environments that are unpleasant have an adverse effect on students' behaviour. Crosnoe, (2006) added that academic failure and inability to achieve goals draws students to smoking, drugs and alcohol which become a new method for them to cope with the alternatives form of social achievement. These students feel that schooling pursuits may become harder but less important for them. Also students behave more defiantly and less cooperatively with teachers perceived by them as unfair and untrustworthy in authority; in contrast, the same students behave conversely with teachers perceived as fair in their authority, and trustworthy. Unclear rules promote school discipline problems, and larger schools tend to have more discipline problems due to a higher incidence of student involvement in gang activities, drug use and vandalism (Cotton and Wikelund, 1990).

Media and Communication Technology such as television, cyber-cafes with computing networks, internet, cinemas and Video compact disk (VCD) somehow or rather has become the source of discipline problems and undesirable act among the students in schools today. Students especially teenagers are exposed to a vast flood of information due to the development of technology. In view of this, finding by Bolston (2006) stated that today students are exposed to a vast and proliferating flood of information and they communicate with the wider world in ways and at inconceivable speeds.

Finally, social environmental factors such as communities and housing areas contribute to discipline problems. Poipoi et al. (2011) stated that youth who live in rural low-income communities have risk profiles that are similar to youth in inner 
cities. Additionally, youth from minority backgrounds tend to have a disproportionately higher number of referrals for school discipline problems than their peers from the majority culture.

\section{Principles, theories, and concepts}

Merton (1985), on modes of adaptation, said that there are things that all individuals want and expect in life but those who lack opportunity will seek out goals by whatever necessary means. According Merton, crime is bred through this process and he develops five possible reactions to such a disparity between goals and means including conformity, innovation, ritualism, retreat and rebellion. From a different perspective, Social Learning Theory by Bandura (1997) stated that learning is not simply a matter of connecting response to a stimulus. It occurs when a person observes and imitates someone else's behaviour. Therefore, learning of any behaviour by students can be due to reinforcement, imitation and identification.

Supporting this, Glasser (2000) stated 95\% of all discipline problems are misguided efforts of children trying to achieve power and all our choices and behaviours are based upon the six basic needs of urgency for survival, power, love, belonging, freedom and fun. Glasser (2000) concluded that indiscipline in school is caused by the family, environment, violence in society, peer relationship boredom, sense of personal failure, a lack of acceptable outlet for communicating problems, and a sense of powerlessness among students. Home factors contribute to violent behaviour including poor relationships between parents and children, the manner of disciplining children at home, and low levels of home supervision (Poipoi et al., 2011).

With this deep lack of positive affirmation, it is easy to see how Curwin and Mendler (1997) observed that students with chronic behaviour problems see themselves as losers and have stopped trying to gain acceptance in normal ways. Learning how to develop self-discipline in students with dignity affords teachers and administrators more time using skills and methodologies that develop positive interactions with students during teaching and learning. Curwin and Mendler (1997) named their model aiming to accommodate this, 'Discipline with Dignity'. This model is a responsibility and empowerment-based versus obedience-based discipline model, which creates an atmosphere of democracy, encouragement, hope and warmth where clearly defined limits (with student input) and skills in resolving conflicts are taught and applied. In view of this, a model is formed to see the contributing factors and approaches to curb the problem (Fig. 1).

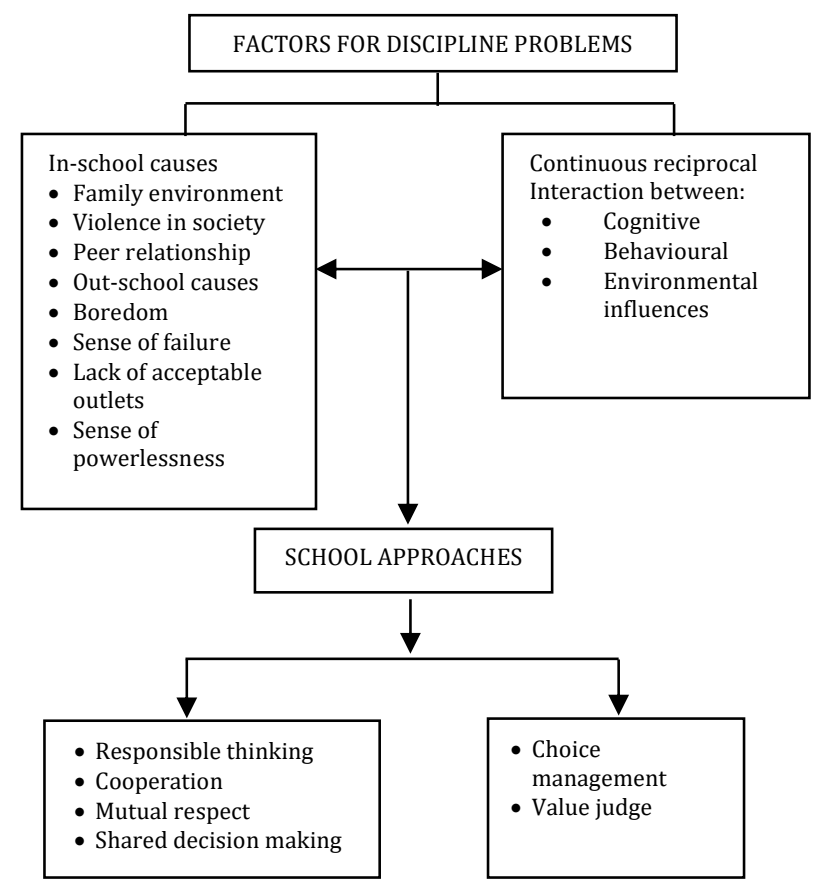

Fig. 1: Theoretical framework (Adapted from Glasser, 2000; Bandura, 1997; Curwin and Mendler, 1997)

The school environment, for reasons mentioned previously, can significantly contribute to discipline problems among a school population. School discipline, which contains rules, routines and procedures, are important in managing a school, especially with teenage students; and this model aims to systemize the fostering a healthy school climate, which is a challenge. It is important, therefore, in operational terms to carry out a thorough study on factors that contribute to poor school behaviour and also how schools may manage their maintenance strategies. Keefe and Jenkins (1997) indicated the positive relationship between good discipline (positive behaviour) and good instruction as facilitative to learning. Johnston et al. (2006) illustrated a direct correlation between academic failure and smoking, drugs and alcohol, 
which supplement academic achievement with negative peer-social achievement.

The overall findings of previous studies on discipline problems in the secondary school clearly indicate that factors contributing to discipline problems are parental factors, peer influence, school environment, social environment and also media and communication technology. The preventive measures initiated from the conceptual framework are believed to be positively influential in addressing prevalent discipline problems in schools. Literature also illustrates that discipline problems in schools can also be dealt more effectively if parents, community and other responsible stakeholders share the responsibility. Thus, how do we reduce these misbehaviours or symptoms? IWe believe that in the case of indiscipline in schools, effective approaches should start from the school itself.

\section{Research objectives}

As such, the purpose of this study is therefore to identify factors contributing to students' indiscipline, and measures or behavioural approaches adopted by the school to curb these problems.

\section{Methodology}

A qualitative research design is adopted to study the discipline problems in school and the behavioural management approaches practised in the school. Information was gathered using semistructured interviews, whilst documented discipline records and counsellor's files were also referred for triangulation purposes. Set question lists were used as an interview guide to seek the perception of respondents on discipline problems, factors contributing to the problem, and the effect of measures initiated by the school to curb problems.

The research was carried out at one secondary school consisting of teenagers from the age of 13 to 17 years and from various ethnic groups. This school was chosen as the site for research because of the high prevalence of discipline problem and the various measures adopted to improve students' behaviour. Numerous discipline problems were identified based on the discipline records, namely; lateness, truancy, vandalism, obscene behaviour, intimidation, extortion, loitering, smoking, gangsterism, impoliteness followed by stealing, keeping long finger nails, threatening, grooming (dress code), long or fashionable hair, rudeness, vandalism, disruption of teaching and learning process, keeping cigarettes and incomplete school work. Truancy tops the list as one of the major discipline problems in this school. A total of 168 cases of truancy were reported in 2011 which comprises 22 per cent of the total case for 2011 . The total case of truancy in 2013 is 12.4 per cent which is lower than 2011 and 2012. Other offences have also decreased, indicating effective indiscipline measures has occurred and worthy of research.
The school is located in an urban area with a large enrolment of 2097. 47 per cent of the students are Chinese, 27 per cent Malay students and 24.3 per cent Indian, and 1.7 per cent other races. Classes are streamed according to student's achievement in examinations. It is a two-session school, located near a commuter station on a large area of land with a residential area at the rear of the school connected by a path. The school is surrounded with walls only on the front portion and covered by secondary forest at the back of the school compound.

The respondents consist of ten teachers - five of them are discipline teachers, two are counsellors and three subject teachers. The primary criterion for the selection is that the respondents are individuals who are involved directly in dealing with student discipline problems and experienced for more than ten years. Six female and four male teachers, between 35 and 50 years of age, comprise a group of five Malays, two Chinese and three Indians. Such selection eliminates the possibility of bias in data based on school activity, gender, and ethnic identity that had no restrictions on answering questions regarding discipline problems and contributory factors. Pseudonyms are used in the report out of findings to preserve the anonymity of the respondents.

\section{Findings and discussions}

\subsection{Factors contributing to discipline problems in the school}

The dominant factors identified to have strong influence on discipline problems are home environment, peer influence, social support, development of medias and communication technology, school culture, and leadership qualities.

\subsubsection{Home environment}

All respondents feel that the roots to delinquency are the youth's family and the environment within the family. Teenagers go astray due to lack of parental attention and guidance. Without love, parental guidance and supervision, some being left with child minders or foreign maids, teenagers are faced with the threat of the disintegration of family values. Parent-child interaction of chronic delinquents often fails to reinforce good behaviours in early childhood. Harsh and inconsistent punishments also contribute to school indiscipline among the teenagers.

Some of the respondents feel that teenagers of this group are not only lacking in parental and moral guidance, in fact spiritual knowledge too. Respondents also commented those youths from families with history of criminal violence, a history of being abused, gang membership and alcohol and drug use are found to be at increased risk for violence. Teenagers with biological parents who have social problems and alcoholic issues are more 
likely to become chronic delinquents if exposed to family conflict at an early age.

There are many students who resort to discipline problems come from broken homes either they are staying in homes with relative or single parents. Boys from broken homes show more anti-social behaviours than girls especially when the mother is the head of the family.

Respondents also stated that authoritarian parents and democratic parents result in different kinds of behaviours in the teenage life. Individuals from democratic parents are more rational; behave well and less involved in unruly behaviours in the schools.

In conclusion, an unsupportive home environment will result in deviant youths and increase the risk of unruly behaviours among the student teenagers. A lack of parental guidance, love, spiritual knowledge and authoritarian parents tend to favour various discipline problems among teenage students. Family backgrounds with a history of abuse, violence and alcoholic parents also contribute to the decline of discipline among students. These unsupportive home environments drive students to seek attention from outsiders who are usually friends sharing a similar predicament.

\subsubsection{Peer influence}

Youth and teenage years are an exciting time because students learn to know themselves, yet it is a risky period when they can engage in unruly behaviour (Papalia and Olds, 1992). The respondents voice out that peer relationships or peer influence as the second highest contributing factors in the decline of discipline in secondary school. They opined peer group influence on the lifestyle and character of teenagers. Peers offer support, reinforcement and confidence due to spending much of their time with those whom they identify and feel comfortable. Thus, when a youth 'falls into the wrong crowd', it can influence him or her to commit delinquent acts. Teenagers need friends for support because teenage years are a period of conflict.

The responses from the respondents imply that the youth need to feel belonging and be recognized. They also want space to embrace values and to find out what they stand for. School is a place where youth gain information and master new skills, but some experience school as a hindrance to personal growth.

\subsubsection{Social environment}

The social environment and living conditions can indirectly cause anti-social behaviour among teenage students in schools. Some feel that congested housing areas without social amenities influence student's behaviour too.

Ethnicity also plays a big role in influencing students' indiscipline. Group identification commonly produces ethnic gang clashes between the
Chinese, Malays and Indians. In conclusion, the social environment such as poor living conditions, condensed housing areas, an absence of public facilities and ethnic disparity do contribute to students' indiscipline in school.

\subsubsection{Media and communication technology}

Media and Communication Technology plays vital role in the decline of discipline among schoolchildren. Television, cyber-cafe-computing networks, internet and cinema has somehow become a source of discipline problems and undesirable behaviour among the students of this school.

A majority of the respondents feel too much violence and sex are represented in television programmes. Respondent 7 who said that media plays an important role in influencing student behaviour supported respondent 9's view.

Respondents also commented that, shopping malls and entertainment centers such as karaoke, and cyber- cafes offer opportunities for truancy.

Overall, it can be concluded that advancement in technology, if not properly managed, has together affected the norms and moral values of the teenage in schools.

\subsubsection{School culture}

School Culture and Curriculum today carries an overly academic focus despite the basic philosophy of education being to produce holistic individuals intellectually, emotionally, spiritually and physically.

Class sizes with forty to forty five students in a class, challenge the teaching process further. Teachers find difficulty in handling the students, especially students with disruptive behaviours, which can result in loud outbursts and disruptive behaviour. Caring and committed teachers play a vital role in instilling positive values to the students.

Indiscipline caused by inter-racial confrontation is quite frequent. Students from different races find it difficult to mingle due to a lack of preparedness in pre-secondary schooling where multi-racial interaction is limited. Most students go to different types of primary school - National Type Primary School, Chinese Type Primary School or Tamil Type Primary School. These students tend to interact within those of similar racial make-up because they speak the same language, share the same culture and eat the same things. Genuine inter-racial friends are rare but not impossible. Teachers must be able to instill confidence to foster understanding and tolerance among the students.

\subsubsection{School leadership}

School leadership is a critical factor in the improvement of a school. A principal, who acts as a leader and works together towards achieving a school's goals, can overcome various problems in school. 


\subsection{Approaches used to curb indiscipline}

School management should play a dominant role in instilling good values and avoid any negative influence on development among at-risk students. In view to this, the school has taken various measures to overcome the problem. Among the measures initiated is the Penalty System Programme (PSP), bonus system, promoting community collaboration, teacher-parent awareness,

\subsubsection{The penalty system programme}

The penalty system Programme (PSP) uses penalty points in managing disciplinary problems. The system is divided into two types; one penalty system with merit (PSM) and the next one penalty system without merit (PSWM). Offences or indiscipline in school is divided into three categories; Category I for light offences, Category II for moderate offences and Category III for serious offences. Serious offences includes vandalism, drugs, glue sniffing, abusive language to teachers and gang fighting while some of the offences in category II involve playing truant, absenteeism and lateness to school. Most of the discipline cases involve the third category such as offences related to disruption of learning and teaching process in classroom and loitering in the school compound during lesson.

The school also carries out a 'point and bonus' system as a tool in the enforcement of school rules and regulations. This helps to measure all types of offences and contributions listed in the student's penalty cards. This measurement or penalty system in the school aims to reduce discipline problems in the school. Basically, schools are seen to have their own rules and regulations to follow in order to maintain the discipline among the students. Students should be informed on specific rules of the schools to avoid later violations. According to Fraenkel and Wallen (2000) all students must be aware and prudent of the school rules before disciplinary action can be administered.

The respondents viewed that the measures taken in administrating discipline problems in the school mostly has resulted in good behaviours among the students.

Community collaboration is important to curb discipline cases which result in suspension and expulsion of students, especially if it involves serious offences such as gang fights. Schools cannot act alone in cases that involve criminal activities such as gambling, gangsterism or vandalism outside the school compound, and is usually forwarded to the concern of the police.

Community collaboration begins by promoting teacher-parent awareness to inculcate conducive learning environments. Parents and schools share the responsibility to promote good values, whereas problems are dealt effectively when both parties work hand in hand.
The school with the help of Parents Teacher Association (PTA) work together with the community in having various supportive activities and motivational programs for the students. Some of the programs that are suitable for schools with multiple discipline problems are intervention programs, and programs such as racial integration programs which are suitable for schools with students from various ethnic.

The school often organizes talks and seminars on social problems such as the danger of smoking and drugs. Students are also exposed to health related talks such as HIV and AIDS. These programs provide avenues for parents to share their views and keep in contact with class teachers regarding their children's academic performance and conduct in school.

Voluntary activities (gotong royong) were also organized to paint the school walls, landscaping and creating mini recreational parks, upgrade the library corners with more resting chairs and pavilion for students to carry out indoor games during leisure hours.

Other programs such as 'Back on Track' for selected students with discipline cases, is an eyeopener for some students. Problematic students are also given the responsibility as class monitors and school prefect positions as opportunities to become leaders.

Finally, remedial programmes were also established for certain students to overcome their academic inability.

\section{Discussion}

This study identifies the home environment, peer influence; social expectation, school culture, the media, and information-communication technology are identified as salient factors contributing to indiscipline in schools.

There is no stage in life that is more complex and troubled than the teenage years, 13 to 19 years old, because it is a transition where the entire human doubts, hesitations and uncertainties appear. Most teenagers feel a sense of belonging when they are in the company of their peers, but the problem starts if they befriended teenagers with disruptive behaviours which mostly result in indiscipline problems in schools. They get support and reinforcement from the peers with whom they identify and feel comfortable. In regard to this, the findings shows that schoolchildren need adults who listen, show respect, and offer advice and guidance but are not over-controlling. This is in agreement with Reyna and Farley (2006), that young people need accurate information so that they are equipped to make competent decisions

Apart from peers, this study also indicates that the impact of media and communication such as television, computer network, VCD's, music and movies, hand phones with MMS with proliferating information inspire them to be defiant. Exposures to violent and uncensored movies, website with pornographic scenes and sites on the screens is 
perceived as a contributing factor too. This is in-line with DeLisi et al. (2013) and Malhotra and Kaur (2015) who found that media exposure can potentially lead to juvenile delinquency.

How can we help them? Parents and teachers can help these teenagers by keeping track on their activities and help them to make better choices in life besides giving them moral, emotional and spiritual support. They should not be too authoritative; in fact in certain cases they should play their role as an understanding friend. These teenagers are not right all the time but they are also not always wrong, so by teaching them to handle their freedom wisely will help them to cope their life in a more positive way. Epstein et al. (2009) stated that one of the best guarantees of a child's success in school is his or her parents' involvement in education. Parents are their first teacher and as such their attitudes about learning and school influence the education of their children from early years through graduation. On the other hand, teachers can help most by supporting the school administrators implementing program to scaffold the at-risk students' attendance. Teacherstudent bond can be strengthened further by establishing a good rapport through various activities that involve the students' participation.

\section{Conclusion}

In summary, the study conclude that indiscipline in school is due to collective factors, namely: Lack of parental supervision; inappropriate parental guidance; negative peer influence; an unsupportive school environment; unaccommodating social environments; and, advance progressions of media and technology. To curb indiscipline, students must first be made aware of the school rules before disciplinary actions can be administered. Nonetheless, schools cannot be expected to act alone to reduce the prevalence of indiscipline. Besides implementation of the Penalty System Program, partnerships between PTA and educational NGO's together with the help of police liaison officers has also proven to be effective in overcoming the menace in school. The school's relentless initiative in organizing various programs to educate teachers, parents and students, has further improved the discipline at the school. Last but not least, is the support from the principal to the discipline committee is the greatest source of motivation for discipline teachers to upgrade the level of discipline among the students in school.

\section{Acknowledgement}

The study was funded by Exploratory Research Grant Scheme, Ministry of Higher Education, Malaysia.

\section{References}

Baker J, Grant S, and Morlock L (2008). The teacher-student relationship as a developmental context for children with internalizing or externalizing behavior problems. School Psychology Quarterly, 23(1): 3-15.

Bandura A (1997). Self-efficacy: The exercise of control. Macmillan, London, UK.

Chazan M, Laing AF, and Davies D (2014). Emotional and behavioural difficulties in middle childhood: Identification, assessment and intervention in school. Routledge Company, Abingdon, UK.

Chevalier JM and Buckles D (2013). Participatory action research: Theory and methods for engaged inquiry. Routledge Company, Abingdon, UK.

Cotton K and Wikelund K (1990). Educational time factors. Northwest Regional Educational Laboratory, Oregon, USA.

Crosnoe R (2006). The connection between academic failure and adolescent drinking in secondary school. Sociology of Education, 79(1): 44-60

Curwin R and Mendler A (1997). As tough as necessary: Countering violence, aggression and hostility in our schools. Association for Supervision and Curiculum Development, Alexandria, Egypt.

DeLisi M, Vaughn MG, Gentile DA, Anderson CA, and Shook JJ (2013). Violent video games, delinquency, and youth violence new evidence. Youth Violence and Juvenile Justice, 11(2): 132142.

Desa A, Yusooff F, and Kadir NBYA (2012). Environmental awareness and education: A key approach to solid waste management (SWM)-A case study of a university in Malaysia. INTECH Open Access Publisher. Rijeka, Croatia.

Epstein JL, Sanders MG, Simon BS, Salinas KC, Jansorn NR, and Van Voorhis FL (2009). In School, family, and community partnerships: Your handbook for action. $3^{\text {rd }}$ Edition, Corwin Press, California, USA.

Fraenkel JR and Wallen NE (2000). How to design and evaluate research in education?. $4^{\text {th }}$ Edition, McGraw- Hill, New York, USA.

Glasser W (2000). School violence from the perspective of William Glasser. Professional School Counseling, 4(2): 77-80.

Johnston LD, O’Malley PM, and Bachman JG (2006). Monitoring the future national survey results on drug use, 1975-2005, Volume I: Secondary school students. National Institute on Drug Abuse, Maryland, USA.

Keefe JW and Jenkins JM (1997). Instruction and the learning environment. One Eye Publication, New York, USA.

Leon B (2006). The trouble with high school. School Administrator, 63(1): 16-20.

Malhotra N and Kaur J (2015). Mass media socialization and delinquent behavior. IAHRW International Journal of Social Sciences Review, 2(4). Available online at: http:// www.mripub.in/index.php/IIJSSR/article/view/1683

Merton RK (1985). George Sarton: Episodic recollections by an unruly apprentice. Isis: A Journal of the History of Science Society, 76(4): 470-486.

MOE (2013). Pelan Pembangunan Pendidikan Malaysia 20132025. Ministry of Education, Putrajaya, Malaysia. Available online at: www. moe. gov. my.

Morales A (1982). The Mexican American gang member: Evaluation and treatment. In: Becerra RM, Karno M, and Escobar J (Eds.), Mental Health and Hispanic Americans: 139155. Clinical Perspectives, Grune \& Stratton, New York, USA.

National Middle School Association (2003). Characteristics of young adolescents. In: Scales PC (Ed.), This We Believe: Keys to Educating Young Adolescents: 53-62. National Middle School Association (now Association for Middle Level Education), Westerville, USA.

O'Connor EE, Dearing E, and Collins BA (2011). Teacher-child relationship and behavior problem trajectories in elementary 
school. American Educational Research Journal, 48(1): 120162.

Onyije AC and Ojedapo DO (2010). Guidance and counseling services for achieving skills development in Nigerian secondary school system: The problems. Journal of Technical Education Research and Development, 3(1): 49-56.

Papalia DE and Olds SW (1978). Human development. McGraw Hill, New York, USA.

Papalia DE and Olds SW (1992). Human development. 5th Edition, McGraw-Hill, New York, USA.

Poipoi MWU, Agak JO, and Kabuka EK (2011). Perceived home factors contributing to violent behaviour among public secondary school students in Western province, Kenya. Journal of Emerging Trends in Educational Research and Policy Studies, 2(1): 30-40.

Reyna VF and Farley F (2006). Risk and rationality in adolescent decision-making: Implications for theory, practice, and public policy. Psychological Science in the Public Interest, 7(1): 1-44
Shahizan H, Tsai CC, and Saw HC (2005). Intrapersonal and interpersonal untuk Remaja. PTS Publication and Distributors, Kuala Lumpur, Malaysia.

Shelley H and Natalie RH (2006). Helping students who are experiencing persistent and/or serious discipline problems to succeed in school: The state of the evidence. In the Conference of Ontario Ministry of Education Research, University of British Columbia, Vancouver, Canada: 18-20. http://www.edu.gov.on.ca/eng/research/hymel.pdf

Silver RB, Measelle JR, Armstrong JM, and Essex MJ (2005). Trajectories of classroom externalizing behavior: Contributions of child characteristics, family characteristics, and the teacher-child relationship during the school transition. Journal of School Psychology, 43(1): 39-60.

Yahaya A, Ramli J, Hashim S, Ibrahim MA, Rahman RR, and Yahaya N (2009). Discipline problems among secondary school students in Johor Bahru, Malaysia. European Journal of Social Sciences, 11(4): 659-675.

Yahaya A, Yahaya N, and Idris F (2012). Aggressive behavior and the influencing factors at five schools in Johor bahru. Elixir Psychology, 42A: 6530-6536. 